Letter to the Editor

\title{
Comparison between surgical outcomes of glaucoma drainage implant surgery performed with and without intraluminal stent
}

Lingwei William Tao, ${ }^{1}$ Alp Atik, ${ }^{1,2}$ Hye J in Kwon, ${ }^{2}$ Catherine Green, ${ }^{1,2}$ Michael Coote, ${ }^{1,2}$ Yu X.G. Kong ${ }^{1,2}$ and J onathan B. Ruddle $e^{1,2,3}$

1. Centre for Eye Research Australia, 32 Gisborne Street, East Melbourne, Victoria, Australia.

2. Royal Victorian Eye and Ear Hospital, 32 Gisborne Street, East Melbourne, Victoria, Australia.

3. Royal Children's Hospital, 50 Flemington Road, Parkville, Victoria, Australia.

Correspondence: Lingwei William Tao, Royal Victorian Eye and Ear Hospital, 32 Gisborne St, East Melbourne, VIC 3012, Australia

Email: Lingwei.tao@eyeandear.org.au

Received 16 December 2019; accepted 30 December 2019

Funding sources / Financial disclosure: None

Conflict of interest: None

This is the author manuscript accepted for publication and has undergone full peer review but has not been through the copyediting, typesetting, pagination and proofreading process, which may lead to differences between this version and the Version of Record. Please cite this article as doi: 10.1111/ceo.13714

This article is protected by copyright. All rights reserved. 
The utilisation of glaucoma drainage implants (GDIs) has increased in recent years for management of glaucoma. However, optimal intraocular pressure (IOP) control in the early postoperative period has remained a challenge in GDI surgery involving non-valved implants. Failure of early IOP control could lead to hypotony-related (IOP $<6 \mathrm{mmHg}$ ) complications such as flat anterior chamber, choroidal effusion and suprachoroidal haemorrhage.(1) Currently, there is no consensus on the optimal technique to prevent early hypotony in non-valved GDIs. We assessed eyes that underwent non-valved GDI surgery with or without intraluminal stenting to compare rates of hypotony and surgical outcomes.

In this retrospective chart review of 90 eyes that underwent GDI surgery by glaucoma subspecialists at The Royal Victorian Eye and Ear Hospital between 2009 and 2014, patients received either a Baerveldt GDI (Baerveldt 250 $\mathrm{mm}^{2} / 350 \mathrm{~mm}^{2}$, Advanced Medical Optics, Santa Ana, Califormia, USA) with coated nylon intraluminal suture stent (Supramid Extra 3-0 polyamide, B. Braun Melsungen AG, Jackson, USA), or a non-stented Molteno GDI (Molteno 3 GS/GL, Molteno Ophthalmic Limited, Dunedin, New Zealand). Preimplantation occlusion of the tube was performed in both GDI types. Molteno GDIs were occluded with an external ligation tie of polygalactin suture (Vicryl, Ethicon US. LLC), while Baerveldt tubes were occluded by the insertion of a polyamide suture to $10 \mathrm{~mm}$ or a point just before the suture obstructed the lumen and would advance no further. Some Baerveldt GDIs also had additional external Vicryl ligation ties. Venting slits were placed in the body of the tube for Molteno GDIs but not Baerveldt GDIs. Primary outcome measures were based on surgical outcome consensus definitions from the World Glaucoma Association. 
The baseline characteristics and treatment outcomes are summarised in Table 1 . The leading glaucoma diagnosis was uveitic, followed by primary open angle and neovascular. Average follow-up duration was 20.39 months. Although there was a significant difference in baseline VA between the two groups in the study, the post-operative relative change in VA did not show any statistically significant difference at 24 months. IOP measurements in the two study groups are plotted in Figure 1 . There was no significant difference in mean pre-operative IOP between the Molteno and the Baerveldt groups ( $28.5 \pm 11.3$ $\mathrm{mmHg}$ and $25.8 \pm 8.0 \mathrm{mmHg}$ respectively, $P=0.19$ ). Compared to the Baerveldt group, the Molteno group had significantly lower mean IOP at day one $(7.30 \pm 9.13 \mathrm{mmHg}$ vs. 16.49 $\pm 9.61 \mathrm{mmHg}, \mathrm{P}<0.001)$ and at week one $(11.41 \pm 11.25 \mathrm{mmHg}$ vs. $17.67 \pm 11.74$ $\mathrm{mmHg}, \mathrm{P}=0.024$ ), but not at subsequent time points. The Molteno group had a significantly higher proportion of patients with IOP $<6 \mathrm{mmHg}$ compared to the Baerveldt group at day 1 (32.35\% VS $12.50 \%, P=0.03)$. A total of 28 eyes (50\%) with Baerveldt GDIs underwent stent removal, with mean time to removal of 20.2 weeks (range 6 to 96 weeks).

The mean survival time was 24.56 months for the Molteno group and 26.02 months for the Baerveldt group (Log-Rank $X^{2}=0.178, P=0.67$ ) (Figure 2). At 2 years, patients in both groups were using an average of 2 glaucoma medications compared to baseline of 4. Between the Baerveldt and the Molteno groups, the qualified success rate was $64 \%$ and $68 \%(P=0.95)$, respectively. Our results are comparable to the qualified tube surgery success rate of $63 \%$ reported by Gedde et al. from the one-year outcome data of the Tube Versus Trabeculectomy study.(2)

There was no significant difference between the two groups in both early and late complications as shown in Table 2. Our complication rates are consistent with previous 
studies, with early hypotony being the most common (3). There were two cases of endophthalmitis in the Baerveldt group, which occurred within the 4 months postoperative period. The first case was due to tube exposure and cultures grew Pseudomonas aeruginosa and Staphylococcus species. The second case had early hypotony and culture negative endophthalmitis. No case of endophthalmitis was reported in the Molteno group. Although the number of cases seen in this study is insufficient to determine a significant difference between the two groups, the overall rate of endophthalmitis is consistent with rates reported in the literature.(4)

There are several limitations to this retrospective study. First of all, we used two different types of GDI with varying plate sizes. Plate size was one factor thought to pre-determine the size of the bleb capsule and thus long-term IOP. However, similar to previous studies, our results showed no significant difference in long-term success rate, complication rate, final IOP, visual acuity and number of medications between the $250 \mathrm{~mm}^{2}$ Baerveldt, 350 mm² Baerveldt and Molteno 3 (175 and $230 \mathrm{~mm}^{2}$ ) implants. $(5,6)$ Secondly there were differences in the baseline characteristics between the Molteno and Baerveldt groups. The Baerveldt group had significantly more congenital and uveitic glaucoma patients - a group of patients more susceptible to complications such as early-postoperative hypotony, (7) whereas the Molteno group had a greater proportion of primary open angle glaucoma and neovascular glaucoma patients. The Baerveldt group was also on average 15 years younger than the Molteno group, with a potentially lower threshold to return to theatre to perform manipulations such as anterior chamber refill. A prospective randomised comparative study will be required to avoid effect of selection bias.

This is to the best of our knowledge the first study to compare the early and long-term outcomes of GDI with and without intraluminal stenting. We found there was no 
statistically significant difference in terms of long term IOP-lowering effect, reduction in anti-glaucoma medication, complete and qualified success, or complication rate. However, a significant difference was identified in the proportion of patients with IOP < $6 \mathrm{mmHg}$ as well as day 1 and week 1 post-operative IOP. This difference in IOP was transient and did not translate into higher rate of complications in the Molteno group. It may have been due to the different proportions of glaucoma subtypes in the two groups. While our study does not provide significant evidence for the use of intraluminal stent in all patients, we recommend this technique be considered in patients with risk factors for hypotony-related complications, such as young age, previous uveitis, high myopia, previous cyclodiode treatment or a past history of hypotony.

\section{REFERENCES}

1. J eganathan VS, Ghosh S, Ruddle JB, Gupta V, Coote MA, Crowston J G. Risk factors for delayed suprachoroidal haemorrhage following glaucoma surgery. $\mathrm{Br}$ J Ophthalmol. 2008;92(10):1393-6.

2. Gedde SJ, Schiffman JC, Feuer WJ, Herndon LW, Brandt JD, Budenz DL. Treatment outcomes in the tube versus trabeculectomy study after one year of followup. AmJ Ophthalmol. 2007;143(1):9-22.

3. Smith MF, Doyle JW, Sherwood MB. Comparison of the Baerveldt glaucoma implant with the double-plate Molteno drainage implant. Arch Ophthalmol. 1995; 113(4):444-7. 
4. Krishna R, Godfrey DG, Budenz DL, Escalona-Camaano E, Gedde SJ, Greenfield DS, et al. Intermediate-term outcomes of 350-mm(2) Baerveldt glaucoma implants. Ophthalmology. 2001;108(3):621-6.

5. Allan EJ, Khaimi MA, J ones J M, Ding K, Skuta GL. Long-term efficacy of the Baerveldt $250 \mathrm{~mm} 2$ compared with the Baerveldt $350 \mathrm{~mm} 2$ implant. Ophthalmology. 2015; 122(3): 486-93.

6. Meyer AM, Rodgers CD, Zou B, Rosenberg NC, Webel AD, Sherwood MB. Retrospective Comparison of Intermediate-term Efficacy of $350 \mathrm{~mm}$ (2) Glaucoma Drainage I mplants and Medium-sized 230-250 mm(2) Implants. J Curr Glaucoma Pract. 2017; 11(1):8-15.

7. Christakis PG, Kalenak JW, Tsai JC, Zurakowski D, Kammer J A, Harasymowycz PJ, et al. The Ahmed Versus Baerveldt Study: Five-Year Treatment Outcomes. Ophthalmology. 2016; 123(10): 2093-102.

\section{TABLES}

\begin{tabular}{|c|c|c|c|}
\hline & Molteno & Baerveldt & $\begin{array}{c}P \\
\text { valu } \\
e\end{array}$ \\
\hline Number & 34 & 56 & \\
\hline Age (Years) & $\begin{array}{c}64.79 \pm 1 \\
9.48\end{array}$ & $49.80 \pm 21.77$ & $\begin{array}{c}<0.0 \\
1\end{array}$ \\
\hline Gender & & & \\
\hline
\end{tabular}

This article is protected by copyright. All rights reserved. 


\begin{tabular}{|c|c|c|c|c|c|c|c|}
\hline \multirow[b]{3}{*}{ Follow Up (months) } & Male & 19 & $\begin{array}{l}56 \\
\%\end{array}$ & 32 & & $\begin{array}{l}57 \\
\%\end{array}$ & \multirow[b]{3}{*}{0.87} \\
\hline & Female & 15 & $\begin{array}{l}44 \\
\%\end{array}$ & 24 & & $\begin{array}{l}43 \\
\%\end{array}$ & \\
\hline & & $\begin{array}{c}19.96 \pm 1 \\
6.58\end{array}$ & & \multicolumn{2}{|l|}{$\begin{array}{c}20.50 \pm 13.3 \\
8\end{array}$} & & \\
\hline \multirow[t]{11}{*}{ Glaucoma Subtype } & NEOVASCULAR & 9 & $\begin{array}{l}26 \\
\%\end{array}$ & UVEITIC & $\begin{array}{l}1 \\
8\end{array}$ & $\begin{array}{l}32 \\
\%\end{array}$ & \\
\hline & $P O A G$ & 5 & $\begin{array}{l}15 \\
\%\end{array}$ & $P O A G$ & $\begin{array}{l}1 \\
2\end{array}$ & $\begin{array}{l}21 \\
\%\end{array}$ & \\
\hline & $\begin{array}{l}\text { STEROID } \\
\text { RESPONSE }\end{array}$ & 4 & $\begin{array}{l}12 \\
\%\end{array}$ & $\begin{array}{l}\text { CONGENI } \\
\text { TAL }\end{array}$ & 6 & $\begin{array}{l}11 \\
\%\end{array}$ & \\
\hline & PACG & 3 & $\begin{array}{r}9 \\
\%\end{array}$ & $\begin{array}{l}\text { NEOVASC } \\
\text { ULAR }\end{array}$ & 5 & $\begin{array}{r}9 \\
\%\end{array}$ & \\
\hline & UVEITIC & 3 & $\begin{array}{r}9 \\
\%\end{array}$ & PACG & 4 & $\begin{array}{c}7 \\
\%\end{array}$ & \\
\hline & CONGENITAL & 2 & $\begin{array}{l}6 \\
\%\end{array}$ & $P X F$ & 4 & $\begin{array}{l}7 \\
\%\end{array}$ & \\
\hline & PXF & 2 & $\begin{array}{l}6 \\
\%\end{array}$ & $\begin{array}{l}\text { TRAUMAT } \\
\text { IC }\end{array}$ & 4 & $\begin{array}{l}7 \\
\%\end{array}$ & \\
\hline & POST VR & 2 & $\begin{array}{l}6 \\
\%\end{array}$ & POST VR & 2 & $\begin{array}{c}4 \\
\%\end{array}$ & \\
\hline & TRAUMATIC & 2 & $\begin{array}{l}6 \\
\%\end{array}$ & $\begin{array}{l}\text { UNKNOW } \\
N\end{array}$ & 1 & $\begin{array}{l}2 \\
\%\end{array}$ & \\
\hline & PIGMENTARY & 1 & $\begin{array}{l}3 \\
\%\end{array}$ & $\begin{array}{l}\text { STEROID } \\
\text { RESPONS } \\
\text { E }\end{array}$ & 0 & $\begin{array}{l}0 \\
\%\end{array}$ & \\
\hline & UNKNOWN & 1 & $\begin{array}{l}3 \\
\%\end{array}$ & $\begin{array}{l}\text { PIGMENT } \\
A R Y\end{array}$ & 0 & $\begin{array}{l}0 \\
\%\end{array}$ & \\
\hline Baseline IOP & & $\begin{array}{c}28.53 \pm 1 \\
1.27\end{array}$ & \multicolumn{3}{|c|}{$25.75 \pm 7.97$} & & 0.2 \\
\hline Baseline LogMAR VA & & $\begin{array}{c}1.10 \pm 1 . \\
02\end{array}$ & \multicolumn{3}{|c|}{$0.51 \pm 0.62$} & & $\begin{array}{c}<0.0 \\
1\end{array}$ \\
\hline $\begin{array}{r}\text { Change in LogMAR } \\
\text { VA Week } 1\end{array}$ & & 0.27 & \multicolumn{3}{|c|}{-0.23} & & $\begin{array}{c}<0.0 \\
1\end{array}$ \\
\hline $\begin{array}{r}\text { Change in LogMAR } \\
\text { VA Year } 2\end{array}$ & & 0.14 & \multicolumn{3}{|c|}{0.23} & & 0.69 \\
\hline
\end{tabular}

This article is protected by copyright. All rights reserved. 


\begin{tabular}{|c|c|c|c|c|c|c|}
\hline Baseline Med & & $\begin{array}{c}3.94 \pm \\
1.32\end{array}$ & & $4.05 \pm 1.21$ & & 0.68 \\
\hline Final Med & & $\begin{array}{c}1.67 \pm \\
1.27\end{array}$ & & $2.02 \pm 1.43$ & & 0.25 \\
\hline Success & Qualified & 23 & $\begin{array}{l}68 \\
\%\end{array}$ & 36 & $\begin{array}{l}64 \\
\%\end{array}$ & 0.79 \\
\hline \multirow{3}{*}{ Failure } & Complete & 3 & $\begin{array}{r}9 \\
\%\end{array}$ & 4 & $\begin{array}{l}7 \\
\%\end{array}$ & 0.95 \\
\hline & & 11 & $\begin{array}{l}32 \\
\%\end{array}$ & 20 & $\begin{array}{l}36 \\
\%\end{array}$ & 0.25 \\
\hline & $\begin{array}{l}\text { Failure due to } \\
\text { hypotony }\end{array}$ & 2 & $\begin{array}{l}6 \\
\%\end{array}$ & 6 & $\begin{array}{l}11 \\
\%\end{array}$ & 0.44 \\
\hline
\end{tabular}

Table 1: Patient Demographic, average follow up, glaucoma type, baseline IOP and Post-op IOP, and treatment outcomes

\begin{tabular}{c|ccc} 
EARLY COMPLICATION & MOLTENO & BAERVELDT & $\begin{array}{c}P \\
\text { VALUE }\end{array}$ \\
\hline HYPOTONY & $9(26 \%)$ & $13(23 \%)$ & 0.70 \\
CHOROI DAL HAEMORRHAGE (1) & $1(3 \%)$ & $0(0 \%)$ & 0.21 \\
CHOROIDAL EFFUSION (3) & $2(6 \%)$ & $8(14 \%)$ & 0.21 \\
TUBE CORNEAL TOUCH (2) & $1(3 \%)$ & $2(4 \%)$ & 0.86 \\
CORNEAL OEDEMA & $4(12 \%)$ & $2(4 \%)$ & 0.14 \\
HYPHAEMA (1) & $7(21 \%)$ & $5(9 \%)$ & 0.12 \\
ENDOPHTHALMITIS & $0(0 \%)$ & $2(4 \%)$ & 0.54 \\
CYCLODIODE & $1(3 \%)$ & $0(0 \%)$ & 0.72 \\
TUBE REMOVAL (1) & $3(9 \%)$ & $2(4 \%)$ & 0.29
\end{tabular}

This article is protected by copyright. All rights reserved. 


\begin{tabular}{c|ccc} 
LATE COMPLICATION & MOLTENO & BAERVELDT & $\begin{array}{c}P \\
\text { VALUE }\end{array}$ \\
\hline HYPHAEMA & $0(0 \%)$ & $1(2 \%)$ & 0.43 \\
CORNEAL DECOMPENSATION & $1(3 \%)$ & $2(4 \%)$ & 0.87 \\
TUBE REMOVAL & $0(0 \%)$ & $4(7 \%)$ & 0.11 \\
CYCLODIODE & $1(3 \%)$ & $1(2 \%)$ & 0.72 \\
SECOND TUBE & $1(3 \%)$ & $0(0 \%)$ & 0.20 \\
RE-POSITION OF TUBE & $0(0 \%)$ & $1(2 \%)$ & 0.08
\end{tabular}

Table 2: Rate of Early and Late Complication between Treatment Groups. In bracket is the number of cases of early complication associated with hypotony. 


\section{FI GURES}

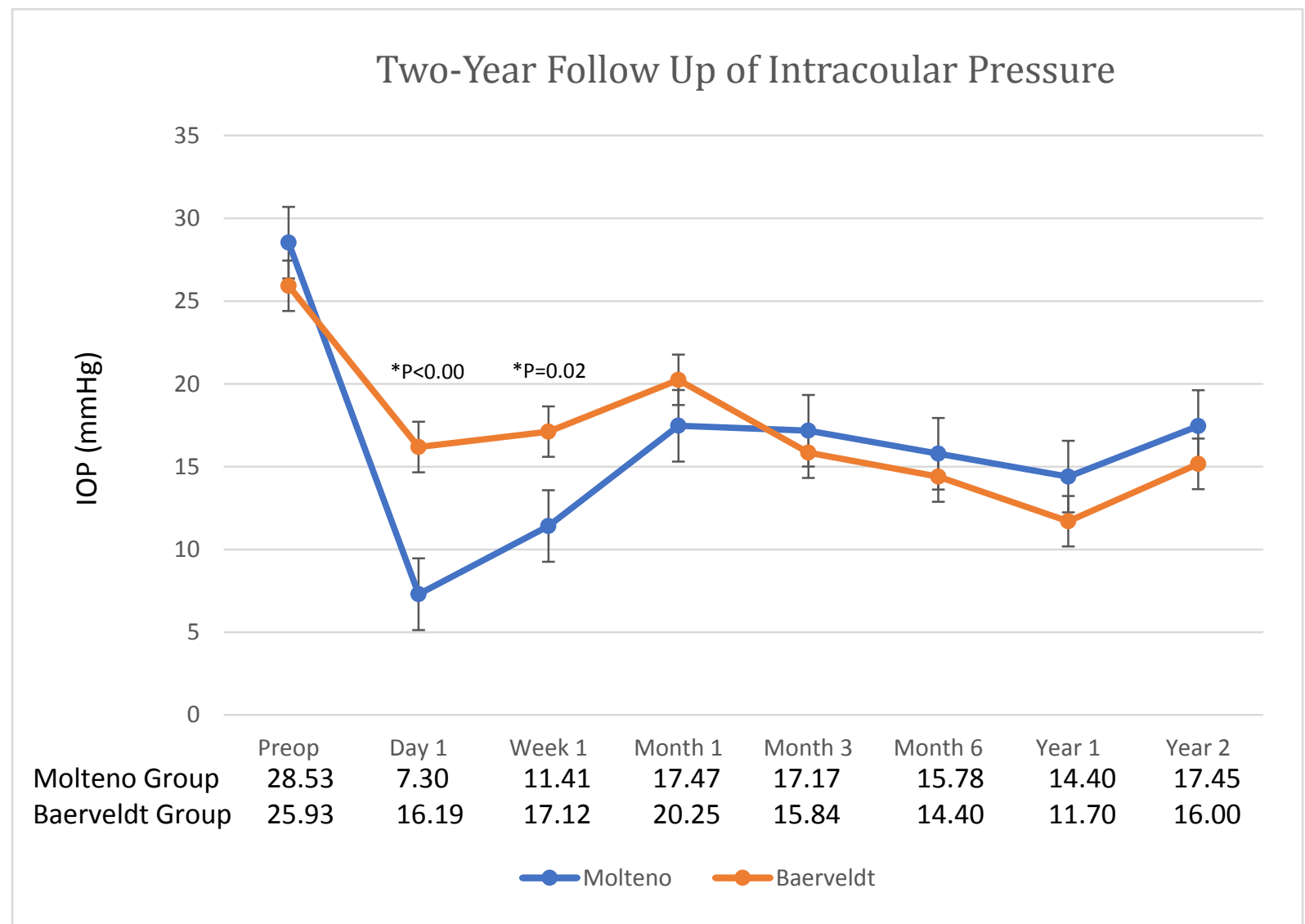

Figure 1: Baseline and Two Year Follow Up Intraocular Pressure between Treatment Groups

This article is protected by copyright. All rights reserved. 


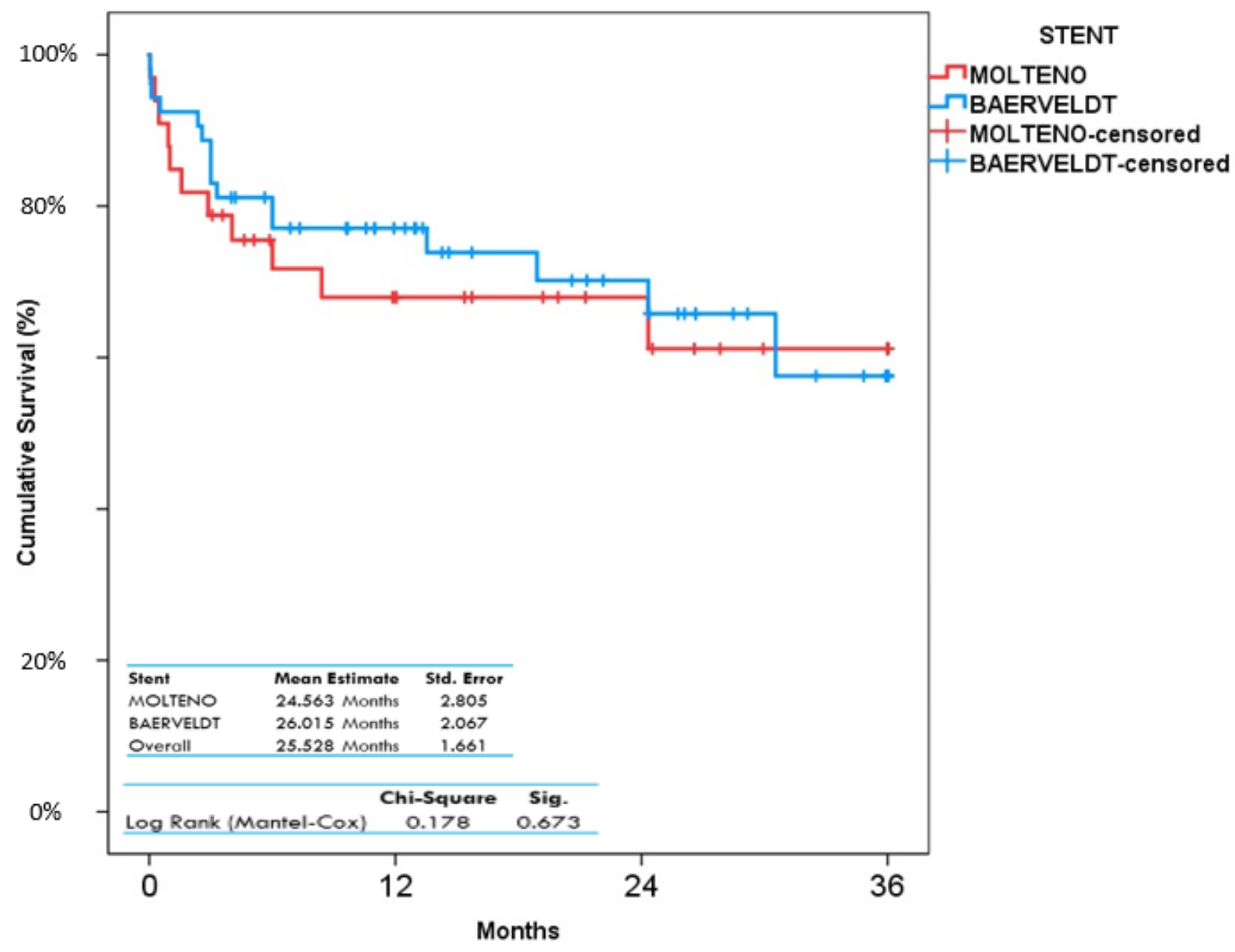

Figure 2: Kaplan-Meier Survival Curve of Cumulative Survival Rate over 36 months by treatment Group

This article is protected by copyright. All rights reserved. 


\section{University Library}

\section{- M I N E R VA}

\section{A gateway to Melbourne's research publications}

Minerva Access is the Institutional Repository of The University of Melbourne

Author/s:

Tao, LW;Atik, A;Kwon, HJ;Green, C;Coote, M;Kong, YXG;Ruddle, JB

Title:

Comparison between surgical outcomes of glaucoma drainage implant surgery performed with and without intraluminal stent.

Date:

2020-05

\section{Citation:}

Tao, L. W., Atik, A., Kwon, H. J., Green, C., Coote, M., Kong, Y. X. G. \& Ruddle, J. B. (2020). Comparison between surgical outcomes of glaucoma drainage implant surgery performed with and without intraluminal stent.. Clin Exp Ophthalmol, 48 (4), pp.525-528. https:// doi.org/10.1111/ceo.13714.

Persistent Link:

http://hdl.handle.net/11343/275368 